The individual in whom this unusual position of the viscera was found had reached the advanced age of eighty-six, and had been a remarkably powerful man in his youth, as I learned from himself and some others who had known him for many years.

Abingdon, Oct. 1848 .

ON

\section{AN INSTANCE OF DISEASE OF THE ANTRUM, PRODUCED BY A FALL.}

\section{Reported by J. L. LEVISON, Esq., Surgeon-Dentist, Brighton.}

Some time since, a young woman of this place, about twentytwo years old, applied for my advice, she having a large swelling on the right cheek, the size of a turkey's egg, the lower or broadest part of the tumour being in a line with the upper lip; the swelling extending so high as to affect the eye and the eyelid. The former was protruded, and the latter almost paralyzed, so that, besides the deformity, the sight of the right eye was seriously affected, and the secretion of tears a source of irritation to the cheek. The tumour was very hard, the surface of the skin red, inflamed, shining, and very painful to the touch. Considering that disease was connected with the pituitary membrane which lines the antrum, I carefully examined the mouth, and observed that the second molar tooth on the affected side was carious, and the gum dark and livid, and so soft, that it appeared to have been deprived of all vitality; and at the same time, the foetor was very offensive. In fact, the gum presented a similar appearance as when there is an effort to throw a piece of dead bone. In the present case there was a well-defined line of demarcation between the affected portion (the cause of the local irritation) and the healthy jaw, for the shape of the diseased gum corresponded to a piece of bone I could move with the slightest pressure. There had not been any teeth extracted on the diseased side of the face, and it occurred to me that the affection of the antrum had been induced by a blow on the face, or from a fall. That, in either case, a large portion of the alveolar process had been fractured, and the molar tooth injured at the same time, by having its periosteum denuded, or so injured that the inflammatory action was set up, and the tooth ultimately destroyed. Having questioned my patient, her answers proved the correctness of my diagnosis. She told me that about ten years since she had fallen down stairs on her face, but that she was not aware that she injured herself at the time, having been stunned. She distinctly recollected that, soon after the accident, the swelling on her face commenced with some uneasiness in her mouth; that at first the tumour was very small, and when it had attained the size of a pigeon's egg, she had applied for advice, and was given something to rub it externally, but without any advantage; and that it had since gone on increasing; that she did not then heed it much, although it was always more or less painful; but that she never suffered any alarm until there seemed every probability she should lose her sight. I mention these particulars because few persons of her class give any history of their cases. It can only be obtained by a species of cross-examination.

I removed the carious molar tooth, with the portion of the dead alveolar process, when a considerable quantity of thick, curdy matter came away, some portions being in different sized lumps. A direct communication was kept up ketween the antrum and the mouth by means of a conical-shaped tube, and the discharge continued, night and day, for some time. For three weeks I injected the antrum, every alternate day, with a lotion of about twenty drops of the chloride of zinc to an ounce of distilled water. About the end of a month the deformity had entirely disappeared, and the affected side had acquired its normal proportions the eye had recovered its natural position and brightness, and the mouth itself had become perfectly healthy. This case forms additional evidence to the opinions I have advanced in previous papers in The LANCEx, that it is impossible for a surgeon-dentist to do his duty if he have not a knowledge of general anatomy and pathology, and also a special information of the mouth, its diseases, and treatment.

Brighton, 1848 .

Appointment.-Dr. Bérard, professor of physiology at the Faculty of Medicine of Paris, was appointed Dean of that Faculty on the 30th of December last.

\section{MRebítus.}

An Introduction to Botany. By JoHn LINDLex, Ph.D., F.R.S.s Professor of Botany in University College, London. Fourth Edition, with corrections and numerous additions. In two vols. pp. 833. London: Longman \& Co. 1848.

The Vegetable Kingdom; or, the Structure, Classification, and Uses of Plants. By JoHN LindeEx, Ph.D. London: Bradbury \& Evans. 8vo. pp. 908.

Is no branch of science has, we were about to say, so great a stride been made within a few years as there has been in botany. This expression, however, may be said to be incorrect, as it is only within a few years that botany has become a science. It would be certainly more correct to say that a new branch of science has been established. It is but a short time since that botany meant little beyond a cataloguing of a series of hard words coined to designate plants. The term now includes a knowledge, not only of the names and uses of plants, but of their external and internal organization, and of their anatomical and physiological phenomena-the laws which regulate the dispersion of species, and moreover the laws of vegetable life by which the luxuries and comforts of mankind may be augmented, \&c. Assisting in progress of developing the science, there is no name more honourably associated than that of Dr. Lindley, and we hail every fresh attempt that he makes to add to our knowledge of the vegetable kingdom with pleasure.

The recent appearance of the work named first at the head of this article eminently gives occasion for also drawing attention to the great and comprehensive work next named, which was sent forth about two years since. Evidently a work of excessive labour and research, we are sure that the pains, which every page of the "Vegetable Kingdom" bespeaks have been bestowed upon it by the author, will be fully compensated for by the estimation in which the work will continue to be held by the botanists of this, and, we may venture to say, of other countries. It is, in truth, the best work on systematic botany that has been produced in any language.

It is now nearly 150 years since our countryman, John Ray, first attempted to classify plants by taking into account more definite characters than were observed in the previous distinction of plants, and in his " Historia Plantarum" left behind him the foundation on which all the natural classification of plants by Jussieu and De Candolle, and others, have been based since his time-a method of classification which Linnæeus himself felt to be the only true one. The artificial method invented by Linnæus, by its apparent simplicity for a time led away most students in botany from the correct path of observation, and made it more difficult for those who laboured in the field of botany to establish in England the only correct and really useful system of classifying plants-viz, according to their general resemblances, or, as it is called, the "natural system." It was long allowed to us to be contented with a most vicious and imperfect elassification of plants. Dr. Lindley must feel much gratified to find the advocates of the old Linnæan system fast dropping away from it, until not even one is left. We remember the time when he stood, as it were, almost alone, the avowed enemy of the old system in England. And we are delighted, in chronicling his success, to be able to appeal to the present volume as a triumphant answer to the once oft-repeated objection to the natural system-viz., the supposed difficulty of mastering the details. If there be somewhat more difficulty in hiving up a knowledge of the characters of the natural orders than in any empirical system, it is amply compensated for by the much greater facility in the determination of genera.

This volume, although in some measure resembling "The Natural System of Botany," cannot be properly called a new edition. It is fairly entitled to the appellation of a new work. The diagnosis of the several natural orders are concise and decided, and the more detailed account of the characters of 